\title{
Noch ein Fall von Vagitus uterinus.
}

Von Medizinalpraktikant Otto Keller in Berlin.

In No. 18 dieser Wochenschrift berichtet Rothschild aus der Breslauer Provinzjalhebammenlehranstalt über einen lall von Vagitns nterinus. Seine Beschrcibung erinnert mich an einen Fall, bei dem ich absichtliclı cin Atmen des Kindes in utero herbeiführte, um ts vor den Frsticken zu bewaluren, und bei dieser Gelegenheit hörte ich sechsbis siebenmal den Kindesschrei im Uterus. Der Fall lagso: Am 18. September 1909 wurde ich als damaliger Hauspraktikant der LniversitätsFrauenklinik au Berlin zu einer 24 jährigen $1 I I$-para gerufen. Dic beiden früheren Partus waren. Steißlagen gewesen mit beidesmal toten Kindern. Bei der inneren Untersuchung fand ich dje Blase stehend, den Xiuttermund handtellergroß. In der Fruchtblase lagen die Fïbe des Kindes. Fs handeite sich also um eine Beckencndlage, und zwar um eine $\mathrm{F} u B$. lage. Herztöne waren git hörbar, die Wehen kräftig. Ioh sprengte die Blase und uherließ dann dic Cieburt sich selbst. Unter guten Wehen wurde das Kind allmählich bis zum Nabel geboren. Nun griff ich zu, um den Partus zu vollenden. Die Lösung der Arme gelang leicht, und ich machte mich daran, den Kopf mit den Voit-Smel]ieschen Handgriff zu ent wickeln. Es war mir aber nicht nöglich, da sich der äußere Muttermund wie ein eisernor Ring krampfhaft um den Hals des Kindes schloß. Bei gewaltsamer Extraktion hätte ich einen Zervixrils mit eventneller Verlängerung desselben in das Corpus uteri riskiert. Das wollte ich nicht. Andersejts eilte die Zeit, das Kind drohte zu crsticken. Auch war es natürlich lebhafter Wunsch der Fitcrn, nach zwei Totgeburten cin lebendes Kind zu haben. Ich ging also mit dem Zcige-, Mittel und Goldfinger der linken Hand am Kinn des Kindes entlang über den liund und die Nase bis zur Stirn, stemmte die geschlossonen drei Finger in der Gegend der Glabella an und lüftete somit den äußeren Muttermund vom Halse des Kindes. Im selben Augenblick schrie das Kind zu meiner großen Ueberraschung. Der Luftzug, der mit clem Abheben des Miutter mundes vor das Gesicht des Kindes gekommon war, hatte offonbar genügt, die Lungen mit Luft zu füllen und den Schrei auszulösen. Lngefähr' sechs-bis siebenmal wiederholte sich dieser Kindsschrei. Schließ. lich gelang es mir, durch kräftiges Dehnen des Muttermundes ihn so zu erweitern, daß 3 ich die Extraktion wagen konnte. Kin Zervixriß fand sich nicht. Das Kind, ein Mädchen, war sehr kebenschwach. Wis hatte offenbar bei den Versuchen, den Muttermund z.n dehnen, neben des Luft auch Fruchtwasser geschluckt. Wiit dem Trachealkatheter entfernte ioh aus der Trachea eine größere lienge blutig tingierten lirucht. wassers. Trotzalledem blieb die große schwiiche bestehen, und das Kind starb nach 1\% Stunden.

Auch in diesen Fall hat das gleichzeitige Aspirieren von Juft und Fruchtwasser dem Kind das Leben genommen. 